\title{
The Implementation Strategy of Outdoor Sports Training in College Physical Education
}

\author{
Dawei Wan \\ Nanyang Institute of Technology, Nanyang, Henan, 473000
}

Keywords: Implementation Strategy, Outdoor Sports Training, College Physical Education

\begin{abstract}
University sports outdoor sports training course design a lot of content, by the water, wild, venues and other forms of training. There are water training, such as rowing, rafting, diving, swimming and other content, field training, climbing and rock climbing, hiking camping, outdoor survival skills and other content, site training with elevated rope and other content. Outdoor sports training is an important part of college physical education, schools and teachers must pay attention to, according to local conditions to choose outdoor sports to strengthen the training of students, cultivate students' comprehensive quality ability.
\end{abstract}

\section{Introduction}

The course content of the outdoor sports training program includes expanding the experience course, returning to the natural curriculum and challenging the self course. The main training methods are water, field and site three parts. Swimming training, diving, rowing, etc. field training content: climbing rock climbing, hiking camping, outdoor survival skills; site training content: refers to the specialized training ground, with the help of certain training facilities, such as: Elevated rope net. In the past, the content of college physical education curriculum is to train the students' physical fitness, greatly neglected the cultivation of students' psychology and adapting to the social ability, together with the development of the project, paid great attention to the development of individual sports, which hindered the cooperation of students' team strengthen. However, the development of outdoor sports training, so that schools and society, naturally together to promote the continuous improvement of college physical education curriculum system to speed up the progress of modern curriculum reform. At the same time, outdoor sports training can play a certain role in physical fitness, through a variety of sports programs can cultivate students' sense of competition, enhance the courage and confidence to overcome difficulties. Outdoor sports training is mainly based on physical activity, through the vivid image, a variety of new experiential courses, the use of a variety of typical teaching scenarios, students can let the physical and mental experience, in the process of self-challenge, to promote students Healthy development of physical and mental. At the same time, the establishment of teaching activities mainly refers to the teachers to play its guiding role and students are the main body of teaching activities. Greatly reflects the teacher has been one-way conduction teaching process smoothly into the teacher and student cooperation in the education process, aims to continue to stimulate students' interest in learning and learning potential.

Through the development of outdoor sports training, students can actively participate in collective activities, to strengthen exchanges and cooperation with other students, the formation of mutual help team atmosphere. In the process of cooperation, enhance the team spirit of the training, the formation of a healthy and healthy state. In addition, for example, when students participate in rock climbing training, students are required to make quick and sensitive judgments due to environmental changes. Therefore, it is also conducive to cultivating students' sensitivity and quality, and reduces the occurrence of safety accidents in outdoor practice. 


\section{The Significance of Outdoor Sports Training in College Physical Education Teaching}

In the past, the content of college physical education curriculum is limited, mainly to train students' physical ability, neglect the development of students' psychological and social adaptability, and many projects are mainly individual sports, and students' cooperation consciousness is not cultivated. Schools and society, naturally closely linked to break through a long time the closed pattern of physical education courses, so that the university sports curriculum system is more perfect to promote the reform of modern curriculum. In addition, outdoor sports training can not only achieve the role of physical fitness, many of them rich, spiritual, passionate sports, but also can cultivate students' sense of competition and social skills. Outdoor sport training is rich in content, close to the actual students, flexible and diverse ways to enhance the students to challenge the difficulties of confidence, and gradually develop students' ability to adapt to society.

The current college students face great pressure on learning, little time to participate in physical exercise, leading to the body in a sub-health state, mental health is also worrying. The school through outdoor sports training, so that students participate in collective activities, and other students help each other, and increase the contact time with nature, is conducive to the growth of college students. Not only that, students in the process of participating in outdoor sport training, to achieve their survival skills and physical fitness. College students in the process of cooperation, to enhance team awareness improve communication and coordination skills, and to maintain a healthy state of mind.

For example, students involved in rock climbing outdoor sports training, students participate in directional movement, rock climbing training process, because the environment is in a state of change, the need for students to quickly and accurately determine the corresponding response. Therefore, this is conducive to cultivating students the spirit of sensitivity both in outdoor practice can use the existing equipment, but also to avoid injury accidents.

\section{Strategies of Implementing Outdoor Sports Training in College Physical Education}

Outdoor sports training for students is a test, very important, in order to ensure the effectiveness of outdoor sports training, to strengthen the construction of professional teachers. Physical education teachers to rational design of outdoor sports training course content, and have a certain ability to implement teaching, personally, for students to do a good job. At present, many college sports teachers' outdoor sports training experience, the understanding of outdoor sports training is not in place, so before the start of outdoor sports training classes, to focus on the training of teachers. Teachers to master the basic outdoor sports training theory, understanding of the project content, training process and organizational methods, and then according to the characteristics of college students, physical education and outdoor sports training together to ensure that the normal outdoor sports training, so that students really get exercise.

Before the outdoor sports training, teachers from the student's interest in the movement, the basic knowledge will be introduced to the students, so that students master the basic skills and technology to outdoor sports. Then teachers according to the existing sports conditions, according to local conditions to choose a reasonable form of outdoor sports to help students improve the level of exercise, ease the pressure of learning and life, relax, threw himself into outdoor activities. Physical education teachers to explain to the students a variety of outdoor sports training knowledge, so that students master the relevant skills and skills, to understand the need to pay attention to place, to ensure the safety of outdoor training and achieve the desired results. In addition, the school also in-depth investigation of the situation of student groups, students understand and recognize the extent of outdoor sports training, starting from the actual situation of students to enhance the outdoor sports training courses targeted to enable students to understand the significance of outdoor sports and the importance of more active participation in outdoor sports training.

In the process of theoretical learning, teachers should use modern information technology to turn boring theoretical learning into interesting teacher-student discussions. Teachers should present the 
process of outdoor sports training to students in the form of video or animation, or play for students outdoor sports open, targeted cross-country competition and other outdoor sports events, and detailed explanation for the students to help students understand the theoretical knowledge. It can let students according to their own quality and hobbies, independent choice of outdoor sports training program, in the course of learning should master the sports knowledge, sports activities and skills, so that training more targeted and scientific. In addition, schools should also strengthen the exchange and cooperation between the different institutions to a strong combination of way to carry out outdoor sports training course research and organizational activities. At the same time between schools can also be through the event competition, to provide students with more extensive outdoor sports training.

University to participate in outdoor sports training, in the difficult field environment to exercise their own quality, enhance the ability of students to survive the field, and hone the students' perseverance, enhance students in the face of difficulties setbacks and confidence, so that students always maintain a good attitude To face the future of life. There is no need for too much money to carry out outdoor sports training, but the school still has to invest the necessary start-up capital to determine the investment under the outdoor sports training program and the equipment used. Usually to outdoor venues for the first, conditional schools can be extended to the water projects and field projects, in determining the outdoor sports training project, the purchase of the corresponding outdoor training equipment. Without affecting the school outdoor sports training under the premise of outdoor sports training base to be open to the outside world, not only for the community to provide services, but also "to material" recycling investment funds, so that the future development of outdoor sports training to provide financial security.

Outdoor sports training based on physical fitness, comprehensive and strong, is an important part of the curriculum of physical education. Outdoor sports has a stimulating and adventurous features, which is its charm, students have a lot of risk factors in training, so in the process of carrying out outdoor sports training in the university, in particular, should pay attention to safety issues, be vigilant to avoid unnecessary accident. In the design of outdoor sports training projects, to consider the possible security risks, can not choose the complex location of the training. Teachers should do a good job in advance check out the work, take a serious safety check, to master the training site prone to dangerous places, do preventive measures. Before the outdoor sports training, teachers remind students to pay attention to safety matters, strengthen supervision and management during training. The school should also be based on the characteristics of outdoor sports training courses, specifically set up an outdoor sports training management agencies, the implementation of a management system to ensure that outdoor sports training in an orderly manner.

Before the course is set up, it is necessary to fully integrate the necessary teaching methods of the outdoor training courses, the design of the teachers and the management mode of the hardware configuration, thus enhancing the initiative of the opening session. With the help of the existing resources inside and outside the school to carry out outdoor sports training services, for the smaller schools, you can use the school around the park and square and other resources. College sports set up outdoor sports training course, the project content can be divided into basic quality training and comprehensive quality training two. Basic quality training is mainly to improve students' self-challenge ability, cultivate the formation of team spirit. And most of the outdoor venues training projects as the center, the economic base of the school can also set up wild and water projects. Comprehensive quality training aims to develop students' team awareness, communication skills and interpersonal skills. Comprehensive quality training is combined with indoor and outdoor environments, through the use of simulated scenarios and experiential models to carry out. In short, the development of outdoor projects to have certain relevance, college physical education combined with the psychological characteristics of students and physical condition, the appropriate outdoor sports training club part of the training content transplanted over. The design of the project should be combined with different disciplines of professional students to carry out professional environmental analysis, to achieve the effect of outdoor sports training.

Before the outdoor sports training, teachers should fully understand the interest of each student's 
movement and impart relevant basic theoretical knowledge, so that students can grasp the basic skills of outdoor sports as soon as possible. Teachers should also take into account the existing level of exercise, according to local conditions to choose the form of outdoor sports, by raising the level of exercise, to ease the pressure of learning for students to create a relaxed and happy mood. College students to participate in outdoor sports training can be hard in the wild environment to exercise their own quality, and strengthen the ability of students to survive the field, so brave to face difficulties and setbacks. When carrying out outdoor sports training programs, schools should use the training programs and equipment required for outdoor sports to determine the investment. To do not affect the school outdoor sports training under the premise of a certain degree of open, so as to carry out the future of outdoor sports training to provide the necessary financial protection.

\section{Conclusion}

It is imperative to carry out outdoor sports training in college physical education teaching, which can improve the students 'professional level and comprehensive literacy level, and ensure the quality and high level of college students' physical education teaching quality. Therefore, in the development of outdoor sports training, we must continue to enrich and innovates the content of sports courses to expand the sports time and space range; the same time, but also to ensure that students in the outdoor sports training process of security, to avoid accidents. Only in this way can we play out the application value of outdoor sports training in college physical education and cultivate excellent physical and technical talents.

\section{References}

[1] Li Cong. On the college physical education teaching "flip classroom" application [J] .New course research (mid-term) .2017 (08)

[2] Mao Jie. Research on the Application of College Physical Education Teaching Based on VR, AR and MR Technology [J].Journal of Wuhan Institute of Physical Education 2017 (09)

[3] Zhang Xuehai. Study on the application of "Muji + flip classroom" teaching mode in college physical education teaching [J]. Liaoning Sports Science and Technology. 2017 (04)

[4] Chen Furong. College sports teaching in the application of micro-class thinking [J]. Test Weekly. 2017 (69)

[5] Huang Daihai. Micro-class in the university sports teaching application research [J]. Prose hundred (new language live page) .2017 (09)

[6] Qiao Peng. Discussion on the Difficulties and Countermeasures of Teaching Students' Ideas in Teaching Physical Education in Colleges and Universities[J]. Shanxi Youth. 2017 (19) 